\title{
Alcohol and Pain: A Translational Review of Preclinical and Clinical Findings to Inform Future Treatment Strategies
}

\author{
Scott Edwards (ID), Leandro F. Vendruscolo, Nicholas W. Gilpin, Marcin Wojnar, and Katie \\ Witkiewitz
}

\begin{abstract}
Alcohol use disorder (AUD) and chronic pain are enduring and devastating conditions that share an intersecting epidemiology and neurobiology. Chronic alcohol use itself can produce a characteristic painful neuropathy, while the regular analgesic use of alcohol in the context of nociceptive sensitization and heightened affective pain sensitivity may promote negative reinforcement mechanisms that underlie AUD maintenance and progression. The goal of this review was to provide a broad translational framework that communicates research findings spanning preclinical and clinical studies, including a review of genetic, molecular, behavioral, and social mechanisms that facilitate interactions between persistent pain and alcohol use. We also consider recent evidence that will shape future investigations into novel treatment mechanisms for pain in individuals suffering from AUD.
\end{abstract}

Key Words: Alcohol Use Disorder, Hyperalgesia, Nociception, Comorbidity, Dependence.

A LCOHOL USE DISORDER (AUD) and chronic pain are frequent, debilitating, and persistent conditions associated with significant individual and social costs (Zale et al., 2015). AUD and chronic pain also commonly co-occur, share many of the same neural substrates, and may also exacerbate neural dysfunction associated with pain transmission, alcohol intoxication, and alcohol withdrawal (Apkarian et al., 2013; Egli et al., 2012; Robins et al., 2019). The goal of this critical review was to extend recent reviews on the topic of alcohol and pain (Egli et al., 2012; Zale et al., 2015). Here, our aim was to establish a broader translational focus that provides an update on recent models and findings from preclinical and clinical studies, including a review of molecular, genetic, behavioral, and social mechanisms that may underlie pain and alcohol use and dependence across species. We also consider the evidence for informing treatment recommendations and future research at the intersection of alcohol and pain.

From the Department of Physiology and Comprehensive AlcoholHIV/AIDS Research Center, (SE, NWG), LSU Health Sciences Center New Orleans, Louisiana; National Institute on Drug Abuse (NIDA), ( $L F V)$, Intramural Research Program (IRP), Baltimore, Maryland; Department of Psychiatry, $(M W)$, Medical University of Warsaw, Warsaw, Poland; Department of Psychiatry, $(M W)$, University of Michigan, Ann Arbor, Michigan; and Department of Psychology, (KW), University of New Mexico, Albuquerque, New Mexico.

Received for publication June 9, 2019; accepted November 28, 2019.

Reprint requests: Scott Edwards, PhD, Department of Physiology, LSU Health Sciences Center, 1901 Perdido Street, MEB 7205, New Orleans, LA 70112; Tel.: 504-568-2669; Fax: 504-568-6158; Email: sedwa5@lsuhsc.edu

(C) 2019 by the Research Society on Alcoholism.

DOI: 10.1111/acer.14260

\section{CHRONIC PAIN PREVALENCE AND COSTS}

Chronic pain, defined as pain that lasts longer than 3 months, is estimated to impact at least $20 \%$ of all individuals in the United States (U.S.) (Dahlhamer et al., 2018), Europe (Breivik et al., 2006), and in other countries worldwide (Goldberg and McGee, 2011). As implied by the name, chronic pain tends to be persistent and debilitating, and few people report "recovery," as defined by a complete absence of pain, even after several years of seeking treatment (Elliott et al., 2002). The impact of pain on health, functioning, and quality of life is profound with devastating effects on social, physical, psychological, and occupational functioning (Goldberg and McGee, 2011). Growing worldwide acknowledgment of disability associated with chronic pain will be recognized in the newest version of the International Classification of Diseases, 11th edition (ICD-11), which will include the diagnosis of chronic pain for the first time (Nugraha et al., 2019), including chronic primary pain (e.g., chronic headache pain) and chronic secondary pain (e.g., musculoskeletal pain due to inflammation). The price of chronic pain is staggering, with direct healthcare costs in the United States estimated to range from $\$ 300$ billion up to at least $\$ 600$ billion per year when including costs associated with workplace productivity loss (Gaskin and Richard, 2012).

\section{AUD PREVALENCE AND COSTS}

Excessive alcohol consumption and AUD are leading causes of morbidity and mortality with enormous societal costs (Bouchery et al., 2011). Well over 3 million deaths worldwide each year are attributable to alcohol, and alcohol contributes to over $5 \%$ of the global burden of disease 
(World Health Organization, 2018). In the United States, it has been estimated that approximately 10 to $13 \%$ of individuals meet criteria for a current (past 12 months) AUD (Grant et al., 2017; Substance Abuse and Mental Health Services Administration, 2018) and up to one-third of all adults in the United States will meet criteria for a lifetime AUD (Grant et al., 2017). Over 88,000 people die each year in the United States due to alcohol-related causes, making alcohol the fourth leading cause of preventable death in the United States (Stahre et al., 2014). Given the widespread prevalence, it is not surprising that excessive alcohol use and AUD are also costly. Estimates in the United States and Europe are staggering, with approximately $\$ 249$ billion U.S. dollars (Sacks et al., 2015) and \$125 billion Euros spent annually (Anderson and Baumberg, 2006). Most of the costs associated with alcohol use and AUD are due to workplace productivity loss, although healthcare expenses, law enforcement, and criminal justice system costs, and costs due to accidents and motor vehicle crashes also contribute (Sacks et al., 2015).

\section{COMORBIDITY OF PROBLEMATIC ALCOHOL USE AND PAIN}

Epidemiological data indicate a strong association between chronic pain and AUD (Beasley et al., 2016), although directionality is difficult to assess (Macfarlane and Beasley, 2015). Prospective examinations of wave 1 and wave 2 data from the National Epidemiological Survey on Alcohol and Related Conditions (NESARC) found that pain interference prospectively predicted the development of AUD (McDermott et al., 2018), and decreases in alcohol consumption were associated with reductions in ratings of acute pain severity 3 years later (Imtiaz et al., 2018). Acute pain frequency (i.e., days with pain) is also associated with the diagnosis of AUD (Edlund et al., 2013). Individuals with chronic pain tend to report higher levels of alcohol use and AUD than the general population (Hoffmann et al., 1995; Vowles et al., 2018) and also report using alcohol to medicate acute pain symptoms (Alford et al., 2016; Brennan et al., 2011; Riley and King, 2009). Likewise, at least one-third to more than one-half of individuals seeking treatment for AUD report chronic, recurrent pain (Boissoneault et al., 2019; Caldeiro et al., 2008; Jakubczyk et al., 2015).

\section{Genetic Mechanisms in the Association Between Pain and Alcohol Use}

Twin studies indicate that up to half of the variability in both AUD and chronic pain may be explained by genetic factors, indicating a large genetic component for both conditions. A comprehensive review of genome-wide association studies (GWAS) and candidate gene association studies (CGAS) that may explain the comorbidity between AUD and chronic pain was recently published (Yeung et al., 2017). The review specifically highlighted genes related to dysregulation of reward and stress systems (e.g., TBX19), genes involved in modulating reward and stress systems (e.g., ADRA1A, HTR7), and those genes that have involvement in the CNS, more broadly (e.g., CDH13). The review also noted the limitation of many prior studies being underpowered to reach the threshold of genome-wide significance. More recent studies that have included much larger sample sizes to detect genome-wide effects include a recent analysis of problem drinking and AUD (Kranzler et al., 2019), chronic back pain (Suri et al., 2018), and headache (Meng et al., 2018), yet polymorphisms that reached genome-wide significance in these larger studies were not overlapping across studies.

To our knowledge, no studies have examined genetic variants associated with the comorbidity of AUD and chronic pain in human samples. Yet, a few recent studies have expanded on the prior review by Yeung and colleagues (2017). An examination of genetic contributions to postoperative pain control across 42 studies concluded AUD was associated with genetic polymorphisms involved with pain sensitivity (Elmallah et al., 2018). Using a case-control design, Lee and colleagues (2018) found phosphatidylinositol 4-phosphate 5 kinase type $1 \mathrm{C}$ (PIP5K1C) gene, which regulates pain signaling and sensitization (Wright et al., 2014), to be associated with AUD among African Americans in a discovery sample. Thus, genetic variants in PIP5K1C may be one potential mechanism for the comorbidity of AUD and chronic pain.

\section{Sex Differences in the Association Between Pain and Alcohol Use}

Sex differences in chronic pain are profound, albeit not well understood (Mogil, 2012). Women are more likely to develop chronic pain, are more sensitive to pain in controlled laboratory studies, and may be at higher risk of developing persistent pain after injury (Linnstaedt et al., 2015; Rosen et al., 2017; Sorge and Totsch, 2017). Sex differences in alcohol use are also notable and complex. Women tend to drink less alcohol than men, although the differences in rate of drinking and heavy drinking by sex are narrowing in recent years (Grant et al., 2017; Khan et al., 2013). Yet, women with AUD tend to have more severe consequences, particularly medical and psychiatric comorbidities as compared to men (Agabio et al., 2017). There are also racial and ethnic differences in pain perception, assessment, and treatment (Campbell and Edwards, 2012), and racial and ethnic differences in alcohol use, AUD, and treatment (Vaeth et al., 2017; Williams et al., 2016). Intersectionality of sex and racial/ethnic differences have also been examined in chronic pain (Forsythe et al., 2011; Meints et al., 2018) and AUD (Glass et al., 2017; Witbrodt et al., 2014). Yet, to our knowledge, only a few studies have explored sex, race, or the intersection of sex and race in the association between pain and AUD.

In samples of older adults, Brennan and colleagues found pain to be associated with lower rates of alcohol use and less 
drinking over time, but more alcohol-related problems, particularly among African Americans (Brennan and Soohoo, 2013) and males (Brennan et al., 2011). Among both men and women, problem drinking in older adulthood was associated with greater pain and greater use of alcohol to manage pain symptoms, which was further associated with worse health outcomes among men and more drinking problems among women (Brennan et al., 2005). Among younger adults, ages 25 to 45 , there is experimental evidence that acute alcohol (approximate BAC $=0.065$ ) may be associated with increased pain threshold among women, and that subjective response to alcohol may be more strongly associated with ratings of pain relief following alcohol administration among women (Hill et al., 2018). Yet, there is also evidence that men with chronic pain may be more at risk of AUD and depression, as well as report a stronger association between pain, depression, and alcohol use, as compared to women (Barry et al., 2013; Brown, 2015; Manubay et al., 2015). Also, in a sample of adults with chronic pain, pain-related anxiety was positively associated with alcohol-related consequences and symptoms of alcohol dependence among males, but not females (Zale et al., 2019).

\section{More Questions than Answers Regarding the Associations Between Pain and AUD in Humans}

The association between pain and alcohol use is clearly complex, and the mechanisms of comorbidity of chronic pain and AUD are not well understood in humans. There is a literature examining analgesic effects of alcohol (Chung and Wang, 2013; Hill et al., 2018; Patberg et al., 1999; Thompson et al., 2017; Woodrow and Eltherington, 1988), and recent empirical work has found acute pain increases the urge to drink (Moskal et al., 2018). Further, preliminary work indicates greater alcohol consumption is associated with momentary reductions in pain (Carpenter et al., 2018). It is also the case that alcohol may exacerbate painful conditions. For example, alcohol is a leading cause of chronic pancreatitis, which is associated with severe abdominal pain (Conwell et al., 2014). Alcohol also increases the risk of accidental injuries, including a greater likelihood of bone fractures, while alcohol may also inhibit proper recovery of fractures (Richards et al., 2017). Heavier alcohol use at the time of injury may also increase the risk of developing chronic pain (Castillo et al., 2006).

Yet, to our knowledge, it is unclear if alcohol continues to provide analgesic effects among those with chronic pain and AUD, or whether alcohol could increase pain hypersensitivity among those with more severe AUD, as seen in the preclinical models, discussed in the next section. Importantly, few studies in humans have directly studied patients with chronic pain and AUD who did not have other comorbidities (e.g., depression, opioid use disorder). Thus, looking to the refinement and utilization of preclinical models is important for gaining a better understanding of the mechanisms that may underlie the interaction of pain and AUD.

\section{PRECLINICAL MODELS TO INVESTIGATE THE INTERSECTION OF AUD AND PAIN MECHANISMS}

Preclinical models provide a valuable tool for studying certain key aspects of AUD-related symptoms, including painlike behaviors. Rodent models, in particular, have been critical to our understanding of the neurobiology of pain and AUD and have directly impacted the availability of treatments for these conditions. In this section, we describe rodent models that are the most frequently used to study pain. We then describe the most commonly used rodent models for studying AUD. Finally, we discuss recently discovered interactions between pain and AUD from the utilization of these models. Only the most commonly used pain and AUD models are described. The general discussion of these models is not intended to be exhaustive. For comprehensive reviews on rodent models of pain (Deuis et al., 2017; Le Bars et al., 2001; Mogil et al., 2010), AUD (Tunstall et al., 2019), and the interaction between pain and AUD (Apkarian et al., 2013; Egli et al., 2012), please refer to the suggested literature.

\section{Rodent Models of Pain}

Pain is defined as an unpleasant sensory and emotional experience that is associated with actual or potential tissue damage or described in terms of such damage (International Association for the Study of Pain). This classification implies that pain is a subjective, emotional experience and thus cannot be directly measured in rodents. A term that is commonly used in rodent models is "nociception," which is not synonymous with pain. Nociception (from the Latin nocere, "to harm or hurt") refers to the process of the transmission of noxious signals (e.g., potentially damaging levels of heat, cold, pressure, or chemicals) by nociceptors ("noci" = noxious; "ceptor" = receptor) to the brain. For simplicity, we use the terms "pain-like" and "nociception" interchangeably herein when referring to rodent models. Allodynia (i.e., a pain response to normally non-noxious stimuli) and hyperalgesia (i.e., an exacerbated pain response to normally noxious stimuli) are also discussed, particularly in the context of alcohol withdrawal-induced allodynia/hyperalgesia. Several rodent models have been developed to mimic acute and chronic pain conditions in humans and study pain's underlying neurobiological mechanisms. Quantitative and qualitative aspects of nociception and alterations of physiology during acute and chronic pain-like states can be measured. Different forms of nociception (e.g., mechanical, thermal, and chemical) can be induced in rodents, the intensity of which can be systematically measured (Deuis et al., 2017). These tests of pain-like states allow researchers to study the mechanisms that are responsible for nociception and test the analgesic efficacy of various approaches (e.g., a drug/medication) to alleviate pain. We briefly describe tests of thermal and mechanical sensitivity that are the more commonly used models of nociception. 


\section{Rodent Models of Thermal and Mechanical Sensitivity}

An important aspect of alcohol dependence, alcohol withdrawal, and chronic pain in humans is changes in thermal and/or mechanical sensitivity, both of which can be evaluated in rodent models using the well-established tail-flick test (D'Amour and Smith, 1941), hot-plate test (Woolfe and Macdonald, 1944), Hargreaves test (Hargreaves et al., 1988), von Frey test (Chaplan et al., 1994), and Randall-Selitto test (Randall and Selitto, 1957).

Models of thermal hyperalgesia are mostly utilized to evaluate inflammatory pain, but animals with neuropathic pain have been shown to exhibit greater sensitivity to thermal stimuli. In the tail-flick model, the rodent's tail is dipped in hot water $\left(50\right.$ to $\left.56^{\circ} \mathrm{C}\right)$ until it retracts its tail. Alternatively, radiant heat (i.e., from a light source) is applied until the tail is retracted. The latency to tail retraction is recorded as a measure of nociception. The maximum duration of exposure to the heat stimulus depends on the temperature (e.g., $20 \mathrm{sec}-$ onds for $54^{\circ} \mathrm{C}$ ) to prevent the risk of tissue damage. The tail withdrawal response is generally considered a spinal reflex (Gregory et al., 2013). In the hot-plate test $\left(50\right.$ to $\left.56^{\circ} \mathrm{C}\right)$, the animal is placed on a hot plate that has an acrylic cylindrical "enclosure" that minimizes the animal's movement. Behavioral responses, such as licking the hind paws and jumping, are commonly used indices of nociception (Vendruscolo et al., 2004). A cutoff (e.g., 20 seconds for $54^{\circ} \mathrm{C}$ ) is set to ensure that no tissue damage occurs. A nociceptive response in the hot-plate test is considered to be supraspinally mediated (Gregory et al., 2013). A caveat is that repeated testing in the hot-plate changes the rats' nociceptive responses due to habituation and learning (Vendruscolo et al., 2004). The Hargreaves test is also commonly used in rodents. Rodents are habituated (e.g., for 15 minutes) to an apparatus that consists of a glass pane upon which the rodent is placed. The rodent is unrestrained, but a transparent acrylic enclosure limits its movements. A moveable infrared generator is placed below the glass pane, and heat is directed toward the hind paw until the animal retracts the paw.

Another common mode of sensitivity investigated is mechanical. In the von Frey model, animals are placed in cages with grid floors that allow access to the paws. After a habituation period, calibrated filaments are applied perpendicularly to the plantar surface of the rodent's paw (most commonly the hind paw), starting from a lower force to a higher force until the animal withdraws its paw. An up-down schedule of forces can be used to determine the paw withdrawal threshold, which is used as an index of mechanical sensitivity (Edwards et al., 2012). Electronic von Frey equipment is also available. In this case, a single testing probe is used, and an electronic device detects the amount of force that is necessary for paw withdrawal. Neither the manual nor electronic probes damage the skin or cause lasting pain. Similarly, the Randall-Selitto test applies an increasing amount of mechanical force to either the fore or hind paws and the withdrawal response is measured (Randall and
Selitto, 1957). For all of the tests described above, painful conditions often lead to lower thresholds, whereas analgesia (antinociception) leads to higher thresholds. Hyperalgesia and allodynia are associated with lower response thresholds. The tail-flick and hot-plate tests are most commonly used to evaluate the analgesic efficacy of drugs, whereas the Hargreaves and von Frey tests are used to evaluate both analgesia and pain-like states (hyperalgesia/allodynia). However, based on the considerable lack of translational efficacy of putative analgesics as examined via these preclinical methods, many researchers are now transitioning away from reflex-based assays toward more cognitive and motivational tasks that are thought to be more related to the negative affective components of pain (e.g., Pahng and Edwards, 2018; Tappe-Theodor et al., 2019).

\section{Rodent Models of AUD}

As for any complex disorder, rodent models do not recapitulate all aspects of AUD or chronic pain. However, important features of AUD can be modeled in rodents (Tunstall et al., 2019; Vendruscolo and Roberts, 2014). Different levels of alcohol intoxication produce physiological and behavioral alterations, such as hypothermia, motor incoordination, anxiolysis, tolerance, and sedation. During withdrawal, such somatic symptoms as hyperthermia, anxiogenesis, tremor, and seizures may be observed. For a comprehensive review of rodent models of AUD, see Tunstall et al. (2019). Important for the present review, alcohol intoxication and withdrawal typically produce analgesia and hyperalgesia, respectively; these aspects of AUD are discussed in the next section.

Perhaps the most important aspect of models of AUD is voluntary alcohol self-administration to the point of achieving a relevant pharmacological effect. Richter and Campbell (1940) reported that laboratory rats voluntarily consume alcohol when given access to a bottle of water and a bottle of alcohol, a model that is popularly known as the 2-bottle choice test. In this model, continuous access to ad libitum alcohol (e.g., $24 \mathrm{~h} / \mathrm{d}$ ) and water typically yields highly fluctuating levels of alcohol consumption. Adaptation of this model has been used to model binge drinking, which is defined by the National Institute on Alcohol Abuse and Alcoholism as an excessive pattern of drinking that leads to blood alcohol levels (BALs) above $80 \mathrm{mg} / \mathrm{dl}$. The use of sweeteners in combination with alcohol to make the solution more palatable to rodents (Ji et al., 2008) has been found to produce such BALs. Other variants of the 2-bottle choice model use intermittent 24-hour access to alcohol (e.g., on Mondays, Wednesdays, and Fridays; Fredriksson et al., 2017; Simms et al., 2008; Wise, 1973) or access to alcohol during the animal's dark (active) cycle (i.e., the drinking-inthe-dark model; Holgate et al., 2017; Thiele and Navarro, 2014), which lead to higher BALs than continuous access to alcohol, in most cases generating peak BALs above $80 \mathrm{mg} /$ 
dl. However, a major drawback of 2-bottle choice procedures is the difficulty in determining when and for how long animals reach relevant BALs. Also, while these models are useful because binge drinking is a common and harmful pattern of alcohol use, they have limited utility in the study of alcohol consumption during alcohol dependence.

To study alcohol dependence, a liquid diet protocol was proposed (Lieber and DeCarli, 1982) where animals are given access to a nutritionally balanced diet that contains alcohol as their sole source of calories. The control group is given a calorically matched diet without alcohol. Both groups are given ad libitum access to water. There are no standardized procedures for the alcohol liquid diet across laboratories, and the concentration of alcohol in the diet varies considerably (e.g., 5 to $35 \%$ ). However, this unique approach results in BALs that are sufficient to induce liver damage, intoxication, tolerance, dependence, and withdrawal (Gilpin et al., 2009; Lee et al., in press). Equally effective in producing alcohol dependence is the chronic, intermittent alcohol vapor exposure model, where animals are typically exposed to alcohol vapor for $14 \mathrm{~h} / \mathrm{d}$ (intoxication), followed by 10 hours with vapor off (withdrawal) Control rats are exposed to air. Food and water are freely available during alcohol vapor exposure. In both the liquid diet and vapor models, the animals in the alcohol group can reach BALs above $200 \mathrm{mg} / \mathrm{dl}$ (i.e., 2.5-times binge-drinking levels) and exhibit motivational signs of withdrawal (e.g., anxiety-like behavior and increase in alcohol drinking during withdrawal) as well as somatic signs of withdrawal (e.g., ruffled fur, porphyrin staining around the eyes, tremor, and abnormal posture; Gilpin et al., 2008; Vendruscolo and Roberts, 2014). A considerable drawback of the liquid diet and vapor models is their forced (i.e., noncontingent) method of alcohol administration, although both models can be combined with operant self-administration to measure volitional alcohol intake, the motivation for alcohol, and compulsive-like alcohol consumption despite punishment. Both models also allow for the maintenance of high BALs over extended periods of time to reliably model dependence symptoms.

\section{Interaction between Alcohol Dependence and Pain-Like Behavior}

Gatch and Lal (1999) performed a seminal set of studies describing the anti-hyperalgesic effects of alcohol in the context of alcohol withdrawal-induced hyperalgesia. Levine and colleagues extended these original investigations to investigate mechanism, using male Sprague Dawley rats given a Lieber-DeCarli alcohol (6.5\%) liquid diet for 12 weeks (Dina et al., 2000, 2006, 2008). Alcohol-exposed rats exhibited hyperalgesia for 4 to 12 weeks in the Randall-Selitto test compared with controls. Alcohol-exposed rats also exhibited mechanical hypersensitivity in the von Frey test and thermal hyperalgesia in the Hargreaves test after 8 weeks of alcohol exposure compared with control rats. Mechanical hypersensitivity in alcohol-exposed rats increased at 5 weeks after the cessation of alcohol, indicating the long-lasting allodynic effects of alcohol withdrawal. Pain-like hypersensitivity was found to be mediated by protein kinase C $\varepsilon$ (Dina et al., 2000, 2006). In another study, Dina et al. (2008) reported that adrenal medullectomy or the blockade of $\beta_{2}$-adrenergic receptors on nociceptors in male Sprague Dawley rats that were subjected to an intermittent alcohol liquid diet procedure (4 days on the diet and 3 days off the diet) prevented/reversed alcohol withdrawal-induced hyperalgesia. $\beta$ adrenergic receptor antagonism was shown to decrease alcohol self-administration in alcohol vapor-exposed dependent rats (Gilpin and Koob, 2010). In addition to participation of the sympathoadrenal axis, daily systemic administration of the glucocorticoid receptor antagonist mifepristone $(30 \mathrm{mg} /$ $\mathrm{kg}$ ) blocked the development of alcohol withdrawal-induced mechanical hyperalgesia. Once hyperalgesia had already been established, repeated, systemic injections of mifepristone and an acute intradermal injection of mifepristone reversed alcohol withdrawal-induced hyperalgesia (Dina et al., 2008). Chronic mifepristone administration was also shown to block the escalation of alcohol drinking in rats that were exposed to alcohol vapor (Vendruscolo et al., 2012). Moreover, acute mifepristone administration reversed the escalation of alcohol drinking in dependent rats (alcohol vapor), without affecting alcohol drinking in nondependent rats (Vendruscolo et al., 2015). Furthermore, chronic mifepristone treatment decreased alcohol drinking in humans with AUD (Vendruscolo et al., 2015). These findings suggest that glucocorticoid receptors play a functional role in dependence-induced pain-like behavior and alcohol drinking.

Using the alcohol vapor model of dependence, Edwards et al. (2012) reported that dependent male Wistar rats exhibited mechanical hypersensitivity, indexed as lower paw withdrawal thresholds in the von Frey test, compared with nondependent rats. Notably, rats that were exposed to alcohol vapor for 4 weeks did not exhibit mechanical hypersensitivity. Only after 8 weeks of alcohol vapor, exposure, when BALs were $200 \mathrm{mg} / \mathrm{dl}$, was mechanical hypersensitivity detected. These findings suggest that alcohol withdrawal-induced allodynia depends on the amount of alcohol exposure. The treatment of rats with a corticotropin-releasing factor- 1 $\left(\mathrm{CRF}_{1}\right)$ receptor antagonist reversed alcohol withdrawal-induced mechanical hypersensitivity. A $\mathrm{CRF}_{1}$ receptor antagonist also decreased alcohol drinking in dependent but not nondependent rats in the alcohol vapor model (Funk et al., 2007), suggesting common dysregulation of the CRF system that contributes to allodynia and the escalation of drinking. Chronic intermittent alcohol vapor exposure is typically experimenter-controlled, and alcohol consumption can be assessed under operant self-administration conditions during withdrawal. However, de Guglielmo et al. (2017) recently developed a model in which male Wistar rats voluntarily self-administer alcohol vapor. The rats were allowed to nose poke for access to alcohol vapor in 8 -hour sessions that were 
conducted every other day. Rats escalated their alcohol vapor self-administration and reached BALs $>200 \mathrm{mg} / \mathrm{dl}$. Similar to passive alcohol vapor exposure, the rats exhibited increase in alcohol intake and the motivation for alcohol compared with rats that did not escalate alcohol self-administration. Additionally, escalated rats exhibited mechanical hypersensitivity in the von Frey test. Again, relatively high BALs (i.e., $200 \mathrm{mg} / \mathrm{dl}$ ) were necessary to produce allodynia, a result that was consistent with the passive alcohol vapor model.

Alcohol-induced hyperalgesia can also be observed in mouse models (Alongkronrusmee et al, 2016; Bergeson et al, 2016; Smith et al, 2016), which allows for powerful genetic manipulations. For example, Alongkronrusmee and colleagues (2016) recently reported that male wild-type (WT) and $\delta$-opioid receptor (DOR) knockout C57BL/6 mice that were allowed to self-administer alcohol $(10 \%)$ versus water for 3 weeks in a 2-bottle choice drinking-in-the-dark $(4 \mathrm{~h} / \mathrm{d})$ procedure exhibited escalation of alcohol intake to $\sim 4 \mathrm{~g} / \mathrm{kg}$ in 4 hours. A few days into alcohol abstinence, both groups exhibited mechanical hypersensitivity in the von Frey test, but this effect was exacerbated in DOR knockout mice. Using a method of passive alcohol delivery, in which mice received 2 or $3 \mathrm{~g} / \mathrm{kg}(20 \%)$ alcohol via oral gavage (i.e., feeding tube) for 15 sessions, mice that received $3 \mathrm{~g} / \mathrm{kg}$ alcohol exhibited significant allodynia compared with the mice that received $2 \mathrm{~g} / \mathrm{kg}$ alcohol when tested during alcohol withdrawal (24 hours). The intrathecal administration of clonidine, an $\alpha_{2}$-adrenergic receptor agonist that is used to treat alcohol withdrawal in humans, reversed alcohol withdrawalinduced allodynia. Notably, allodynia persisted for 4 to 7 days in mice that voluntarily drank alcohol, whereas it persisted for 4 weeks in mice that received higher doses of alcohol via gavage. Again, DOR knockout mice exhibited exacerbated allodynia compared with WT mice. The pharmacological blockade of DORs with naltrindole in alcoholnaïve mice produced an allodynic effect, and a low dose of naltrindole that did not produce allodynia per se prolonged the duration of alcohol withdrawal-induced allodynia. These findings provide evidence of the participation of DORs (and $\alpha_{2}$-adrenergic receptors in the spinal cord) in mediating alcohol withdrawal-induced allodynia.

We discussed above the effects of chronic alcohol exposure on pain-like behavior. Another intriguing research question is the effects of pain-like conditions on alcohol drinking, and a few recent studies have begun to address this relationship. González-Sepúlveda et al. (2016) induced a chronic neuropathic pain-like state via partial sciatic nerve ligation in male CD1 mice. Cold and mechanical allodynia confirmed a painlike state in mice with partial sciatic nerve ligation (compared with sham-operated, control mice). Sciatic nerve-ligated mice also exhibited increases in anxiety- and depression-like behavior compared with control mice. Using the 2-bottle choice drinking-in-the-dark paradigm, mice in a pain-like state consumed significantly greater, albeit transitory, amounts of alcohol compared with control (nonpain) mice.
These animals had not been exposed to alcohol before surgery. However, alcohol drinking did not alleviate the thermal allodynia that was associated with the neuropathic pain-like state. Butler and colleagues (2017) also found increased levels of drinking in male $\mathrm{C} 57 \mathrm{BL} / 6 \mathrm{~J}$ mice following surgical destabilization of the medial meniscus, a model of osteoarthritis. The findings that are discussed above clearly indicate that rodents exhibit many aspects of pain and AUD that are also observed in the human condition. Exposure to alcohol, either voluntarily or passively, may lead to the escalation of alcohol drinking and promote pain-like behaviors. Pain-like conditions may in turn also lead to an increase in alcohol drinking. However, exposure to high amounts of alcohol, which may be challenging in models of voluntary drinking, appears to be critical for the reliable detection of hyperalgesia-like behaviors.

Finally, as mentioned above the motivational and affective components of pain have started to be more thoroughly investigated in rodent models. A potential model for this purpose was recently described by Pahng and Edwards (2018). This model incorporates a non-reflex-based method to measure pain avoidance-like behavior in rats. The model consists of exposing animals to a bright compartment that is naturally aversive to rodents. To escape from this environment, the rodent needs to run across probes of varying heights to reach a dark, less aversive compartment. The latency to exit onto the nociceptive probes is used as index of pain avoidance-like behavior, which is expected to be longer in animals in a pain-like state. Use of this test in animals experiencing drug and alcohol withdrawal might be challenging because withdrawal produces both anxiety- and pain-like behaviors, which are opposite motivational components of this model. However, Pahng and colleagues (2017) revealed increases in pain avoidance-like behavior in opioid-dependent animals under conditions that did not produce differences in anxiety-like behavior in this test. This study also revealed significant, yet modest, correlations in hyperalgesialike behaviors measured via von Frey versus pain avoidance tests, suggesting that these 2 measures detect overlapping yet potentially distinct aspects of pain-related behaviors in animals. Behavioral measurement of the differential contributions of somatic versus motivational/affective components of pain may also correspond to distinct neurobiological substrates, and these relationships likely have important ramifications for future therapeutic strategies.

\section{PRECLINICAL FINDINGS IN RODENT MODELS OF ALCOHOL DEPENDENCE AND HYPERALGESIA}

Ascending and descending nociceptive circuitry intimately interacts with the neural substrates of alcohol reinforcement (Egli et al., 2012). The search for neurobiological correlates of hyperalgesia in the context of alcohol dependence has recently discovered several new mechanisms and promising targets for medications development for both pain and AUD. As one example, Ye and colleagues have performed 
an extensive set of studies focused on the lateral habenula (LHb) using a chronic, intermittent alcohol-drinking paradigm (Fu et al., 2015). The LHb is implicated in the regulation of aversive behaviors and is therefore well positioned to mediate important aspects of negative affect associated with alcohol withdrawal and drinking to relieve negative affect states. Glutamatergic neurotransmission and hyperexcitability of the $\mathrm{LHb}$ is manifest during withdrawal, and this process appears to be driven by enhanced functions of TRPV1 vanilloid receptors (Gregor et al., 2019) and suppression of M-type potassium channels (Kang et al., 2019). One viable therapeutic target in the LHb-mediating AUD symptoms is the orphan G protein-coupled receptor GPR139 (Kononoff et al., 2018). Antagonism of GPR139 with JNJ-63533054 reduced both escalated drinking and hyperalgesia symptoms in alcohol-dependent rats. The endogenous ligand for GPR139 is unclear at the present time, but may relate to either tryptophan/serotonin signaling (Liu et al., 2015), adrenocorticotropic hormone (ACTH), and/or melanocytestimulating hormone (Nohr et al., 2017).

Stimulation of endogenous cannabinoid systems represents another emerging area of analgesic development, along with some very promising preliminary studies. As one example, systemic $\mathrm{CB} 2$ receptor stimulation alleviates hyperalgesia symptoms in an animal model of chronic pancreatitis pain induced by an alcohol/high-fat diet (Zhang et al., 2014). Because CB2 receptors are predominantly distributed outside of the central nervous system, targeting these receptors may produce fewer undesirable psychotropic side effects. Endocannabinoid signaling might reduce pain-like symptoms due to their stress-buffering capacities (Morena et al., 2016) or via anti-inflammatory actions (Katz et al., 2015). Targeting systemic inflammatory processes via endocannabinoid signaling or other processes would appear to be a highly valuable strategy, although sex differences may need to be more closely investigated. For example, the tetracycline derivative tigecycline was found efficacious in reducing mechanical and thermal hyperalgesia in binge-drinking male mice, although this treatment actually increased pain-like sensitivity in females (Bergeson et al., 2016). Although the precise mechanism of tigecycline is still debatable (Oliveros and Choi, 2017), these findings highlight vital importance of investigating sex as a factor in all pain studies, especially given the fact that females are disproportionately affected across most pain syndromes. Bergeson and colleagues recommended additional studies to clarify inflammatory or other mechanisms that may drive the sex-disparate effects of tigecycline. In a similar vein, Kash and colleagues recently discovered that CFA inflammation increased hyperalgesia in both male and female mice, but increased alcohol drinking only in males (Yu et al., 2019). Thus, a better understanding of basic pain-alcohol interactive mechanisms driving sex differences in females versus males is warranted and will likely produce more breakthroughs for the benefit of both sexes.

\section{Emerging Circuitry and Molecular Signatures of Alcohol Withdrawal Hyperalgesia}

A majority of the previous work examining the neurobiology of alcohol has focused on the investigation of individual brain regions, although how central stress and nociceptive circuits are engaged and potentiated in the state of alcohol dependence is a rapidly developing area of preclinical research. Recent work from our group showed that alcoholdependent rats exhibit weaker connectivity between the central amygdala $(\mathrm{CeA})$ and ventrolateral periaqueductal gray during withdrawal. Furthermore, optogenetic activation of vlPAG-projecting $\mathrm{CeA}$ neurons attenuates alcohol withdrawal hyperalgesia, whereas inhibition of vlPAG-projecting $\mathrm{CeA}$ neurons produces thermal hyperalgesia in otherwise experimentally naïve animals (Avegno et al., 2018). The goal of circuit-level analysis of alcohol-related hyperalgesia should be to facilitate the identification of potential treatment targets in humans with AUD living with pain. This can be achieved by establishing the molecular signature of cells that modulate pain and nociception via projections to specific downstream brain regions. If specific receptor subtypes are preferentially enriched on specific sets of projection neurons, then pharmacological modulation of those receptors may present a unique opportunity to modulate that circuit for reducing pain-like outcomes with minimal off-target effects. Focusing on the $\mathrm{CeA}$ as one potential example, chronic alcohol exposure and withdrawal alter MC4R expression in CeA, and site-specific antagonism of MC4Rs in $\mathrm{CeA}$ reverses alcohol withdrawal hyperalgesia (Avegno et al., 2018). MC4Rs are expressed at most levels of the ascending and descending pain circuitry and may induce plasticity via effects on AMPA receptor trafficking to the membrane (Caruso et al., 2014); therefore, it would be of interest to know whether MC4R expression is enriched specifically in cells linking these pain modulation regions (e.g., on the postsynaptic membranes of vlPAG-projecting cells in the CeA). This information may be especially impactful because prior work showed that intranasal delivery of an MC4R antagonist blocks alcohol withdrawal hyperalgesia (Roltsch Hellard et al., 2017). The corticotropin-releasing factor type-1 receptor (CRFR1) may be similarly leveraged to modulate specific circuits for reducing pain in individuals with AUD. For example, CRF and CRFR1 mRNA and protein levels are highly expressed in the CeA (e.g., Funk et al., 2006), CRFR1 modulation of CeA synaptic transmission is altered by alcohol dependence (Roberto et al., 2010), and CRFR1 antagonism in CeA reverses hyperalgesia induced by nicotine dependence and predator odor stress (Baiamonte et al., 2014; Itoga et al., 2016). It remains to be determined whether CRFR1 effects in CeA on hyperalgesia can be attributed to their expression on specific subsets of CeA projection cells. Future work will undoubtedly build on these initial circuit-level findings and also identify roles for new as yet unidentified circuits in alcohol withdrawal hyperalgesia. 


\section{Social Aspects of Pain in the Context of Alcohol}

In addition to pain relief, the facilitation of social interaction is another important reinforcing property of alcohol, including the emotional construct of empathy in the context of pain. In a recent study, the neural substrates mediating the enhancement of empathetic-like behavior by alcohol were investigated (Sakaguchi et al., 2018). This study found that observation of mice receiving foot shocks recruited subsets of neurons in the anterior cingulate cortex (ACC) that also corresponded to experiences of pain in the observer mouse. This phenomenon was further strengthened by alcohol $(1.5 \mathrm{~g} / \mathrm{kg})$, although the noncontingent nature of alcohol administration may limit the applicability of findings. These data complement a series of investigations in drinking animals, suggesting that alcohol withdrawal-induced hyperalgesia may also be transmitted to conspecifics (Smith et al., 2016; Walcott et al., 2018). Indeed, the social transfer of hyperalgesia may represent an adaptive biobehavioral process to facilitate the communication of dangers within a group of animals. Interestingly, chemogenetic inactivation of the ACC reduced hyperalgesia symptoms in both alcohol-exposed mice and their bystander partners (Smith et al., 2017). These recent insights demonstrate the preclinical potential to investigate important social components of affective pain that may directly relate to the fundamental reinforcing properties of alcohol in human populations.

\section{CLINICAL MODELS TO INVESTIGATE THE INTERSECTION OF AUD AND PAIN MECHANISMS}

As noted above, there have been few clinical studies examining chronic pain and AUD populations, and more work is needed to explore this comorbidity in human samples. Given the available preclinical and clinical models of pain and alcohol use, there is great potential to bridge bench to bedside in informing future treatment strategies and new research directions for understanding the comorbidity of chronic pain and AUD. In this section, we review approaches to studying pain and alcohol use in humans and have attempted to align, when possible, with the preclinical approaches, described above.

\section{Clinical Models of Pain}

Unlike preclinical models of pain, it is not ethical to randomly assign individuals to have a chronic pain condition, and thus, most studies of pain induction in humans are based on acute pain manipulations or provoked sensitization models that are designed to mimic aspects of neuropathic pain. Importantly, human experimental pain models provide a bridge to preclinical pain models and provide the opportunity to evaluate mechanisms of pain severity, pain sensitization, and analgesia. Similar to the preclinical models, human experimental pain models can also be characterized by targeting mechanical stimulation (e.g., von Frey filaments use to pinprick, pressure applied via pinching or algometry of the muscles), thermal stimulation (e.g., cold pressor, radiant heat, and burn injury), and chemical stimulation (e.g., capsaicin injection or topical application, mustard oil, hypertonic saline injections), yet each model of experimental pain has shortcomings (Reddy et al., 2012). Further, the lack of a chronic pain experimental model is a limitation of clinical research and necessitates that associational studies conducted with chronic pain patients are still critical for gaining insights into chronic pain and comorbid conditions.

\section{Clinical Models of AUD}

Similarly, it is not ethical to randomly assign individuals to have an AUD, and thus, most experimental studies of alcohol use in humans are based on human laboratory studies of alcohol self-administration, alcohol challenge studies, and studies of alcohol cue- and stress-reactivity (Ray et al., 2018; Yardley and Ray, 2017). Experimental studies involving alcohol administration are typically conducted with nontreatment seeking individuals or drinkers without AUD (Enoch et al., 2009); however, there are several measures that can be informative for research into the clinical characteristics of AUD, including subjective response to alcohol, self-reported craving for alcohol, amount of alcohol consumed or self-administered versus placebo controls, and cue-induced or stress-induced drinking behavior (Litten et al., 2012). Double-blind placebo-controlled alcohol administration studies (either self-administered or experimenter administered) are the gold standard for assessing alcohol's pharmacological effects and craving or subjective response to alcohol, given known alcohol expectancy effects that could be present in unblinded or uncontrolled studies (Stacy et al., 1990). Similar to the case of chronic pain, ethical concerns about alcohol administration among patients with AUD mean it is critical that associational studies are conducted among patients with AUD when asking questions about the intersection of pain and alcohol use among individuals with AUD.

\section{Interaction Between Alcohol Use and Pain in Humans}

Older laboratory-based studies have examined analgesic effects of alcohol in humans (Brown and Cutter, 1977; Cutter et al., 1979; Cutter et al., 1986; Stewart et al., 1995) and have generally found that alcohol reduces acute pain (Thompson et al., 2017). Expectancies for pain reduction partially explained the effects in these prior studies (Egli et al., 2012). More recent studies using placebo-controlled designs have found additional evidence that alcohol produces analgesic effects, which may be moderated by family history of AUD and neuroticism (Ralevski et al., 2010). Yet, these prior studies have focused on acute pain-reducing effects and not effects of alcohol on pain sensitization and hyperalgesia, which is more important for understanding the role of alcohol in chronic pain. 
Recent work by Arout and colleagues (2016) used a novel intradermal capsaicin model to produce hyperalgesia within a double-blind placebo-controlled within-subjects design of 2 alcohol doses $(\mathrm{BrAC}=0.04$ and $\mathrm{BrAC}=0.10)$ versus placebo among a small sample of healthy social drinkers $(n=18)$. Results indicated that alcohol significantly attenuated the capsaicin-induced hyperalgesia, particularly in the high-dose alcohol condition, with $30 \%$ reduction in hyperalgesia in the high alcohol condition and a $10 \%$ reduction in hyperalgesia in the low alcohol condition. Similarly, in a laboratory study of capsaicin-induced pain induction versus placebo among a sample of hazardous drinkers $(n=61)$, Moskal and colleagues (2018) found that individuals in the pain condition reported significantly greater urge to drink and greater intention to use alcohol. Results from both of these recent studies suggest that using alcohol to relieve chronic pain may be partially explained by alcohol's effect in reducing hyperalgesia and greater desire to drink when experiencing pain.

\section{Emerging Studies on Neuroadaptations and Neural Circuitry in Humans}

AUD and chronic pain share much of the same underlying neurocircuitry and both are complex disorders with heterogeneous and extensive impacts throughout the central nervous system (CNS). For example, the prefrontal cortex may serve to regulate cognitive, affective, and motivational aspects of both pain processing and alcohol consumption. However, stress and reward systems are also involved in modulating pain, experience of pain relief, and AUD. Numerous neurotransmitter systems have been implicated with shared genetic underpinnings likely influencing neural adaptations in both AUD and chronic pain. Yet, to our knowledge, no studies have examined the neural circuitry of chronic pain and AUD in human clinical samples and we could only identify 2 studies that examined neural correlates of substance use among chronic pain patients (Boissoneault et al., 2017; Petre et al., 2015). For discussion of the overlapping neural adaptations and circuitry, we recommend prior reviews on the topic (Apkarian et al., 2013; Egli et al., 2012; Elman and Borsook, 2016; Yeung et al., 2017). The current review focuses on the few recent empirical studies that have examined potential neurobiological mechanisms of acute or chronic pain and alcohol or other drug use.

To test reward system involvement in the transition from acute pain to chronic pain (i.e., pain chronification) among smokers versus nonsmokers, Petre and colleagues (2015) conducted secondary data analyses from a longitudinal neuroimaging study of 68 individuals with subacute chronic back pain (duration of 4 to 12 weeks) who were followed for 1 year. Smoking was significantly associated with the persistence of back pain at 1 year, and this effect was mediated by functional connectivity between the nucleus accumbens (NAc) and medial prefrontal cortex (mPFC) during a pain rating task. Specifically, smokers had significantly greater connectivity between the NAc and mPFC. Moreover, greater functional connectivity between the NAc and the mPFC predicted greater likelihood of pain persistence at the 1-year follow-up. The investigators also found a reduction in functional connectivity of the NAc-mPFC among a small group of patients $(n=9)$ who quit smoking during the study. These results provide support for the hypothesis that corticostriatal circuitry is involved in the development of chronic pain and that individuals who engage in addictive behavior (smoking, in this case) may be at greater risk for chronic pain via greater coupling of the NAc and $\mathrm{mPFC}$.

Boissoneault and colleagues (2017) examined associations between alcohol use and hippocampal volume among 40 women with fibromyalgia ( $45 \%$ of whom also had insomnia). Results indicated that any alcohol consumption over the 14 days prior to a magnetic resonance imaging (MRI) scan (average drinks/d $<1$ drink) was associated with significantly lower pain intensity and greater hippocampal volume, bilaterally, as compared to abstainers. Pain duration and total amount of alcohol consumption were not associated with hippocampal volume. Heavier drinkers and those with AUD were not included in the sample, and thus, it is impossible to know whether associations (or lack thereof) would be identified in an AUD sample. Given meta-analytic evidence of reduced hippocampal volume among individuals who engage in binge drinking and those with AUD (Wilson et al., 2017), it is potentially the case that some of the abstainers in the Boissoneault study were former heavy drinkers or that low levels of drinking may be protective among women with fibromyalgia.

\section{Social Aspects of Pain in the Context of Alcohol in Humans}

Alcohol intoxication may also inhibit neural responses associated with pain empathy, defined by neural reactions to viewing images of people experiencing a painful stimulus (e.g., knife about to cut into a hand, stubbing a toe on a board). Specifically, a double-blind placebo-controlled within-subjects study of 21 heavy social drinkers found that a $0.85 \mathrm{~g} / \mathrm{kg}$ dose of alcohol, as compared to placebo, was associated with less activity in the dorsal ACC, right anterior insula, and right interior frontal gyrus during the pain image versus the no pain image (Hu et al., 2018). In addition, functional connectivity between the right anterior insula and fronto-parietal areas (including the dorsolateral prefrontal cortex) was increased while viewing pain images in the placebo condition, but not in the alcohol condition. These results suggest that acute alcohol administration may attenuate neural reactivity to viewing pain images among others and may have important implications for understanding how alcohol may dull pain responding, more generally.

\section{TREATMENT IMPLICATIONS AND TREATMENTS TARGETING COMORBID CHRONIC PAIN AND AUD}

Pain is a significant risk factor for alcohol relapse during and following alcohol treatment (Witkiewitz et al., 2015). 
Pain reduction during alcohol treatment is associated with lower alcohol relapse risk (Jakubczyk et al., 2016), and heavier drinking is associated with greater pain severity, pain interference, and less pain coping among chronic pain patients receiving long-term opioid therapy (Larance et al., 2016). Targeting the nexus of pain and alcohol use, as well as aberrant opioid use among patients prescribed opioid therapy (Landsman-Blumberg et al., 2017; Witkiewitz and Vowles, 2018), may be critical to improve treatment outcomes among individuals impacted by pain and AUD. Comorbidity is particularly concerning and important to target given that alcohol is commonly taken along with opioids and other substances among individuals experiencing chronic pain (Landsman-Blumberg et al., 2017; Larance et al., 2016; Novak et al., 2016; Vowles et al., 2018). Combined use of alcohol, opioids, and sedatives is particularly worrisome (Kelley et al., 2018; McCabe et al., 2006; Schepis et al., 2018; Votaw et al., 2019) given the increased risk for overdose from using these drugs in combination (Gudin et al., 2013; Jones et al., 2014).

Pharmacotherapy approaches that may be effective include those that target brain reward and stress systems. For example, there is preliminary evidence that naltrexone, a Food and Drug Administration-approved medication for AUD, may be effective in the treatment of chronic pain (Patten et al., 2018) and extended-release naltrexone may be particularly useful in the treatment of co-occurring chronic pain, AUD, and opioid use disorder (OUD) (Hartung et al., 2014; Korthuis et al., 2017; Latif et al., 2019). However, individuals with OUD need to be fully detoxified prior to naltrexone treatment and compliance with naltrexone treatment is a major issue. There is preliminary data that acamprosate may be more effective for individuals who engage in drinking primarily to relieve negative affect (Roos et al., 2017) and it is unclear whether acamprosate may also be more effective for individuals who are drinking to relieve negative affect mediated pain. Likewise, medications that are commonly used off-label for the treatment of AUD (Kranzler and Soyka, 2018) including gabapentin, selective serotonin and norepinephrine reuptake inhibitors, and topiramate are commonly used in the treatment of a variety of pain conditions (Ong et al., 2019; Silberstein, 2017). To date, no randomized clinical trials have systematically studied pharmacotherapy options for individuals with comorbid AUD and chronic pain, and additional research is needed to test the efficacy of pharmacotherapy in this population.

Behavioral intervention approaches developed specifically for comorbid AUD and chronic pain are also lacking. However, there are promising preliminary data to support the efficacy of cognitive-behavioral treatment (CBT) for comorbid pain and substance use disorders (Barry et al., 2019; Morasco et al., 2016), although CBT has been shown to be modestly effective for AUD (Magill and Ray, 2009). Mindfulness- and acceptance-based interventions are effective for pain (McCracken and Vowles, 2014) and AUD
(Bowen et al., 2014), and may be effective for the treatment of comorbid pain and AUD, particularly given recent evidence of effectiveness in the treatment of comorbid pain and OUD (Garland et al., 2014). Given the chronic and enduring nature of chronic pain, an acceptance-based approach that improves functioning and is less concerned with pain relief may be particularly important for individuals who have a history of using alcohol for pain relief. Noninvasive brain stimulation approaches, including transcranial magnetic stimulation and transcranial direct current stimulation, may also be promising tools given evidence of effectiveness for the treatment of pain (Ong et al., 2019) and AUD (Stein et al., 2018). Finally, physical exercise may be beneficial for improving health outcomes and quality of life among both chronic pain patients (Geneen et al., 2017) and individuals with AUD (Hallgren et al., 2017).

\section{FUTURE DIRECTIONS FOR RESEARCH AND TREATMENT OF COMORBID CHRONIC PAIN AND AUD}

Although the analgesic utility of alcohol has been well known for millennia, studies of the relationship between chronic pain and AUD in laboratory animals and humans remain in an incipient stage, and few satisfactory approaches are available for managing either of these devastating conditions. Despite the limitations of preclinical models, they have provided important new information about the biological basis of pain, AUD, as well as their interactions. Continued refinement of rodent models and improved insights into how chronic pain interacts with multiple physiological and psychiatric disease processes in humans will be necessary to propel future research discoveries (Fig. 1). Motivational/ affective components of pain need to be considered in both preclinical and clinical studies to further our understanding of pain, AUD, and their common comorbidity for the development of future treatment strategies. For example, it is important to expand preclinical and clinical models to consider pain interference, as an important target for improving functioning and quality of life among individuals with AUD and chronic pain.

Bridging the preclinical and clinical models presented in this review, future research on chronic pain and AUD would benefit from in-depth study of hypersensitivity and whether individuals with AUD and chronic pain experience analgesia or whether alcohol consumption causes greater hypersensitivity to pain among individuals with AUD and chronic pain. Similarly, the preclinical models examining neurobiological mechanisms of alcohol withdrawal-induced hyperalgesia are critical for informing our targets for alcohol relapse prevention among individuals with AUD and chronic pain during early abstinence from alcohol. Based on preclinical data (Dina et al., 2008), mifepristone could represent a promising medication for chronic pain patients with AUD, and several studies are currently underway to examine the effects of mifepristone in humans. Preclinical work on the 


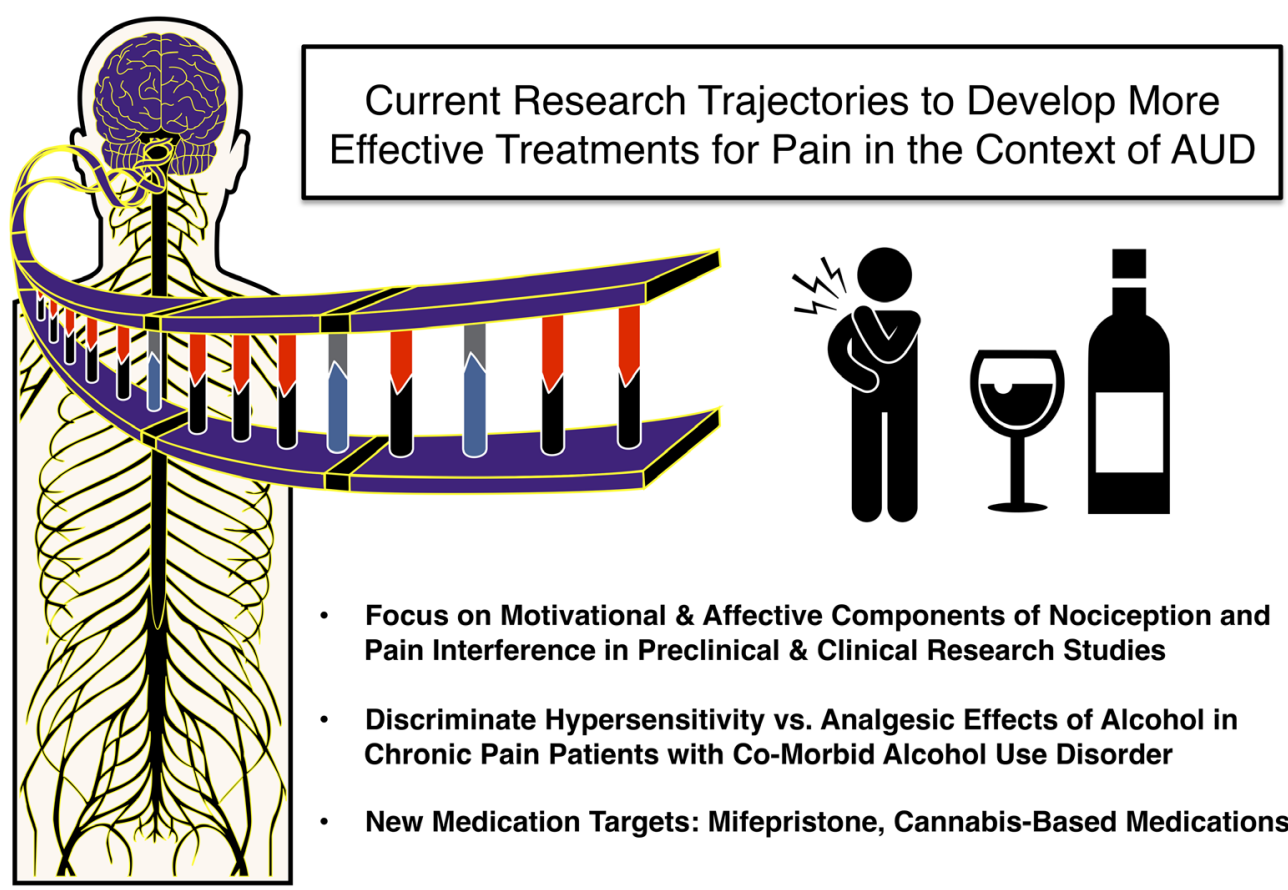

Fig. 1. Recommended research trajectories for the treatment of pain and AUD.

analgesic effects of the endocannabinoid system (Zhang et al., 2014) would suggest that future work would also benefit from examining cannabis-based medications given some promising data in the areas of pain (Mücke et al., 2018) and AUD (Turna et al., 2019), although the potential harms of cannabis would need to be weighed against the potential benefits (Hall, 2001; Subbaraman and Kerr, 2019; Weinberger et al., 2016).

In conclusion, AUD and chronic pain are both complex and heterogeneous conditions with high prevalence, high rates of comorbidity, and both produce devastating social, human, and economic costs. Preclinical and clinical research has only recently considered the comorbidity of AUD and chronic pain, and more research is needed to understand the mechanisms of chronic pain and AUD, and to develop treatment targets that might be effective in reducing suffering related to both pain and AUD. Future work focused on potential moderators of treatment effectiveness, such as sex/gender, genetic background, age, pain modality, and comorbid substance use (Ditre et al., 2019), is also critically important.

\section{ACKNOWLEDGMENTS}

Preparation of this review was generously supported by National Institute on Alcohol Abuse and Alcoholism grants AA025996 (SE), AA022328 (KW), AA023305 (NWG), AA026531 (NWG), AA026022 (NWG), by the Department of Veterans Affairs grant BX003451 (NWG), and by the National Institute on Drug Abuse Intramural Program (LFV).

\section{CONFLICTS OF INTEREST}

$\mathrm{SE}$ is a consultant for Avanos Medical, Inc., a private company focused on the development of medical devices for pain management. NWG owns shares in Glauser Life Sciences, Inc., a private company with interests in developing treatments for mental health diagnoses. LFV, MW, and KW have no conflicts related to this work.

\section{REFERENCES}

Agabio R, Pisanu C, Gessa GL, Franconi F (2017) Sex differences in alcohol use disorder. Curr Med Chem 24:2661-2670.

Alford DP, German JS, Samet JH, Cheng DM, Lloyd-Travaglini CA, Saitz R (2016) Primary care patients with drug use report chronic pain and selfmedicate with alcohol and other drugs. J Gen Intern Med 31:486-491.

Alongkronrusmee D, Chiang T, van Rijn RM (2016) Involvement of delta opioid receptors in alcohol withdrawal-induced mechanical allodynia in male C57BL/6 mice. Drug Alcohol Depend 167:190-198.

Anderson P, Baumberg B (2006) Alcohol in Europe - public health perspective: report summary. Drugs Educ Prev Policy 13:483-488.

Apkarian AV, Neugebauer V, Koob G, Edwards S, Levine JD, Ferrari L, Egli M, Regunathan S (2013) Neural mechanisms of pain and alcohol dependence. Pharmacol Biochem Behav 112:34 41.

Arout CA, Perrino AC, Ralevski E, Acampora G, Koretski J, Limoncelli D, Newcomb J, Petrakis IL (2016) Effect of intravenous ethanol on capsaicininduced hyperalgesia in human subjects. Alcohol Clin Exp Res 40:14251429.

Avegno EM, Lobell TD, Itoga CA, Baynes BB, Whitaker AM, Weera MM, Edwards S, Middleton JW, Gilpin NW (2018) Central amygdala circuits mediate hyperalgesia in alcohol-dependent rats. J Neurosci 38:7761-7773.

Baiamonte BA, Valenza M, Roltsch EA, Whitaker AM, Baynes BB, Sabino V, Gilpin NW (2014) Nicotine dependence produces hyperalgesia: role of corticotropin-releasing factor-1 receptors (CRF1Rs) in the central amygdala (CeA). Neuropharmacology 77:217-223. 
Barry DT, Beitel M, Cutter CJ, Fiellin DA, Kerns RD, Moore BA, Oberleitner L, Madden LM, Liong C, Ginn J, Schottenfeld RS (2019) An evaluation of the feasibility, acceptability, and preliminary efficacy of cognitivebehavioral therapy for opioid use disorder and chronic pain. Drug Alcohol Depend 194:460-467.

Barry DT, Pilver CE, Hoff RA, Potenza MN (2013) Pain interference and incident mood, anxiety, and substance-use disorders: findings from a representative sample of men and women in the general population. J Psychiatr Res 47:1658-1664.

Beasley MJ, Macfarlane TV, Macfarlane GJ (2016) Is alcohol consumption related to likelihood of reporting chronic widespread pain in people with stable consumption? Results from UK biobank. Pain 157:2552-2560.

Bergeson SE, Nipper MA, Jensen J, Helms ML, Finn DA (2016) Tigecycline reduces ethanol intake in dependent and nondependent male and female C57BL/6J mice. Alcohol Clin Exp Res 40:2491-2498.

Boissoneault J, Lewis B, Nixon SJ (2019) Characterizing chronic pain and alcohol use trajectory among treatment-seeking alcoholics. Alcohol (Fayetteville, N.Y.) 75:47-54.

Boissoneault J, Vatthauer K, O'Shea A, Craggs JG, Robinson M, Staud R, Berry RB, Perlstein W, Waxenberg L, McCrae CS (2017) Low-to-moderate alcohol consumption is associated with hippocampal volume in fibromyalgia and insomnia. Behav Sleep Med 15:438-450.

Bouchery EE, Harwood HJ, Sacks JJ, Simon CJ, Brewer RD (2011) Economic costs of excessive alcohol consumption in the U.S., 2006. Am J Prev Med 41:516-524.

Bowen S, Witkiewitz K, Clifasefi SL, Grow J, Chawla N, Hsu SH, Carroll HA, Harrop E, Collins SE, Lustyk MK, Larimer ME (2014) Relative efficacy of mindfulness-based relapse prevention, standard relapse prevention, and treatment as usual for substance use disorders: a randomized clinical trial. JAMA Psychiatry 71:547-556.

Breivik H, Collett B, Ventafridda V, Cohen R, Gallacher D (2006) Survey of chronic pain in Europe: prevalence, impact on daily life, and treatment. Eur J Pain 10:287-333.

Brennan PL, Schutte KK, Moos RH (2005) Pain and use of alcohol to manage pain: prevalence and 3-year outcomes among older problem and nonproblem drinkers. Addiction 100:777-786.

Brennan PL, Schutte KK, SooHoo S, Moos RH (2011) Painful medical conditions and alcohol use: a prospective study among older adults. Pain Med 12:1049-1059.

Brennan PL, Soohoo S (2013) Pain and use of alcohol in later life: prospective evidence from the health and retirement study. J Aging Health 25:656-677.

Brown RL (2015) Functional limitation, pain, and alcohol use: exploring gender differences in the mediating role of depressive symptoms. J Stud Alcohol Drugs 76:809-817.

Brown RA, Cutter HSG (1977) Alcohol, customary drinking behavior, and pain. J Abnorm Psychol 86:179-188.

Butler RK, Knapp DJ, Ulici V, Longobardi L, Loeser RF, Breese GR (2017) A mouse model for chronic pain-induced increase in ethanol consumption. Pain 158:457-462.

Caldeiro RM, Malte CA, Calsyn DA, Baer JS, Nichol P, Kivlahan DR, Saxon AJ (2008) The association of persistent pain with out-patient addiction treatment outcomes and service utilization. Addiction 103:1996-2005.

Campbell CM, Edwards RR (2012) Ethnic differences in pain and pain management. Pain Manag 2:219-230.

Carpenter R, Wood PK, Trull TJ (2018) Physical pain as an aversive stimulus: negative reinforcement of alcohol and opioid use in daily life in chronic pain patients. Alcohol Clin Exp Res 42:324A.

Caruso V, Lagerstrom MC, Olszewski PK, Fredriksson R, Schioth HB (2014) Synaptic changes induced by melanocortin signalling. Nat Rev Neurosci 15:98-110.

Castillo RC, MacKenzie EJ, Wegener ST, Bosse MJ (2006) Prevalence of chronic pain seven years following limb threatening lower extremity trauma. Pain 124:321-329.

Chaplan SR, Bach FW, Pogrel JW, Chung JM, Yaksh TL (1994) Quantitative assessment of tactile allodynia in the rat paw. J Neurosci Methods 53:55-63.
Chung M, Wang C (2013) Can alcohol consumption be an alternative treatment for fibromyalgia? Arthritis Res Ther 15:126.

Conwell DL, Lee LS, Yadav D, Longnecker DS, Miller FH, Mortele KJ, Levy MJ, Kwon R, Lieb JG, Stevens T, Toskes PP, Gardner TB, Gelrud A, Wu BU, Forsmark CE, Vege SS (2014) American Pancreatic Association Practice Guidelines in chronic pancreatitis: evidence-based report on diagnostic guidelines. Pancreas 43:1143-1162.

Cutter HS, Jones WC, Maloof BA, Kurtz NR (1979) Pain as a joint function of alcohol intake and customary reasons for drinking. Int J Addict 14:173182.

Cutter HS, O'Farrell TJ, Whitehouse J, Dentch GM (1986) Pain changes among men from before to after drinking: effects of expectancy set and dose manipulations with alcohol and tonic as mediated by prior experience with alcohol. Int J Addict 21:937-945.

D'Amour FE, Smith DL (1941) A method for determining loss of pain sensation. J Pharmacol Exp Ther 72:74-79.

Dahlhamer J, Lucas J, Zelaya Carla, Nahin R, Mackey S, DeBar L, Kerns R, Von Korff M, Porter L, Helmick C (2018) Prevalence of chronic pain and high-impact chronic pain among adults - United States, 2016. MMWR Morb Mortal Wkly Rep 67:1001-1006.

de Guglielmo G, Kallupi M, Cole MD, George O (2017) Voluntary induction and maintenance of alcohol dependence in rats using alcohol vapor self-administration. Psychopharmacology 234:2009-2018.

Deuis JR, Dvorakova LS, Vetter I (2017) Methods used to evaluate pain behaviors in rodents. Front Mol Neurosci 10:284.

Dina OA, Barletta J, Chen X, Mutero A, Martin A, Messing RO, Levine JD (2000) Key role for the epsilon isoform of protein kinase $\mathrm{C}$ in painful alcoholic neuropathy in the rat. J Neurosci 20:8614-8619.

Dina OA, Khasar SG, Alessandri-Haber N, Green PG, Messing RO, Levine JD (2008) Alcohol-induced stress in painful alcoholic neuropathy. Eur J Neurosci 27:83-92.

Dina OA, Messing RO, Levine JD (2006) Ethanol withdrawal induces hyperalgesia mediated by PKCepsilon. Eur J Neurosci 24:197-204.

Ditre JW, Zale EL, LaRowe LR (2019) A reciprocal model of pain and substance use: transdiagnostic considerations, clinical implications, and future directions. Annu Rev Clin Psychol 15:503-528.

Edlund MJ, Sullivan MD, Han X, Booth BM (2013) Days with pain and substance use disorders: is there an association? Clin J Pain 29:689-695.

Edwards S, Vendruscolo LF, Schlosburg JE, Misra KK, Wee S, Park PE, Schulteis G, Koob GF (2012) Development of mechanical hypersensitivity in rats during heroin and ethanol dependence: alleviation by $\mathrm{CRF}_{1}$ receptor antagonism. Neuropharmacology 62:1142-1151.

Egli M, Koob GF, Edwards S (2012) Alcohol dependence as a chronic pain disorder. Neurosci Biobehav Rev 36:2179-2192.

Elliott AM, Smith BH, Hannaford PC, Smith WC, Chambers WA (2002) The course of chronic pain in the community: results of a 4-year follow-up study. Pain 99:299-307.

Elmallah RK, Ramkumar PN, Khlopas A, Ramkumar RR, Chughtai M, Sodhi N, Sultan AA, Mont MA (2018) Postoperative pain and analgesia: Is there a genetic basis to the opioid crisis? Surg Technol Int 32:306-314.

Elman I, Borsook D (2016) Common brain mechanisms of chronic pain and addiction. Neuron 89:11-36.

Enoch MA, Johnson K, George DT, Schumann G, Moss HB, Kranzler HR, Goldman D, National Advisory Council on Alcohol Abuse and Alcoholism (2009) Ethical considerations for administering alcohol or alcohol cues to treatment-seeking alcoholics in a research setting: can the benefits to society outweigh the risks to the individual? A commentary in the context of the National Advisory Council on Alcohol Abuse and Alcoholism - Recommended Council Guidelines on Ethyl Alcohol Administration in Human Experimentation (2005). Alcohol Clin Exp Res 33:1508-1512.

Forsythe LP, Thorn B, Day M, Shelby G (2011) Race and sex differences in primary appraisals, catastrophizing, and experimental pain outcomes. J Pain 12:563-572.

Fredriksson I, Adhikary S, Steensland P, Vendruscolo LF, Bonci A, Shaham Y, Bossert JM (2017) Prior exposure to alcohol has no effect on cocaine self-administration and relapse in rats: evidence from a rat model that does 
not support the gateway hypothesis. Neuropsychopharmacology 42:10011011.

Fu R, Gregor D, Peng Z, Li J, Bekker A, Ye J (2015) Chronic intermittent voluntary alcohol drinking induces hyperalgesia in Sprague-Dawley rats. Int J Physiol Pathophysiol Pharmacol 7:136-144.

Funk CK, O’Dell LE, Crawford EF, Koob GF (2006) Corticotropin-releasing factor within the central nucleus of the amygdala mediates enhanced ethanol self-administration in withdrawn, ethanol-dependent rats. J Neurosci 26:11324-11332.

Funk CK, Zorrilla EP, Lee MJ, Rice KC, Koob GF (2007) Corticotropin-releasing factor 1 antagonists selectively reduce ethanol self-administration in ethanol-dependent rats. Biol Psychiatry 61:78-86.

Garland EL, Manusov EG, Froeliger B, Kelly A, Williams JM, Howard MO (2014) Mindfulness-oriented recovery enhancement for chronic pain and prescription opioid misuse: results from an early-stage randomized controlled trial. J Consult Clin Psychol 82:448-459.

Gaskin DJ, Richard P (2012) The economic costs of pain in the United States. J Pain 13:715-724.

Gatch MB, Lal H (1999) Effects of ethanol and ethanol withdrawal on nociception in rats. Alcohol Clin Exp Res 23:328-333.

Geneen LJ, Moore RA, Clarke C, Martin D, Colvin LA, Smith BH (2017) Physical activity and exercise for chronic pain in adults: an overview of Cochrane Reviews. Cochrane Database Syst Rev 4:CD011279.

Gilpin NW, Koob GF (2010) Effects of $\beta$-adrenoceptor antagonists on alcohol drinking by alcohol-dependent rats. Psychopharmacology 212:431439.

Gilpin NW, Richardson HN, Cole M, Koob GF (2008) Vapor inhalation of alcohol in rats. Curr Protoc Neurosci Chapter 9:Unit 9.29.

Gilpin NW, Smith AD, Cole M, Weiss F, Koob GF, Richardson HN (2009) Operant behavior and alcohol levels in blood and brain of alcohol-dependent rats. Alcohol Clin Exp Res 33:2113-2123.

Glass JE, Rathouz PJ, Gattis M, Joo YS, Nelson JC, Williams EC (2017) Intersections of poverty, race/ethnicity, and sex: alcohol consumption and adverse outcomes in the United States. Soc Psychiatry Psychiatr Epidemiol 52:515-524.

Goldberg DS, McGee SJ (2011) Pain as a global public health priority. BMC Public Health 11:770.

González-Sepúlveda M, Pozo OJ, Marcos J, Valverde O (2016) Chronic pain causes a persistent anxiety state leading to increased ethanol intake in CD1 mice. J Psychopharmacol 30:188-203.

Grant BF, Chou SP, Saha TD, Pickering RP, Kerridge BT, Ruan WJ, Huang B, Jung J, Zhang H, Fan A, Hasin DS (2017) Prevalence of 12month alcohol use, high-risk drinking, and DSM-IV alcohol use disorder in the United States, 2001-2002 to 2012-2013: Results from the National Epidemiologic Survey on Alcohol and Related Conditions. JAMA Psychiatry 74:911-923.

Gregor DM, Zuo W, Fu R, Bekker A, Ye JH (2019) Elevation of transient receptor potential vanilloid 1 function in the lateral habenula mediates aversive behaviors in alcohol-withdrawn rats. Anesthesiology 130:592608.

Gregory NS, Harris AL, Robinson CR, Dougherty PM, Fuchs PN, Sluka KA (2013) An overview of animal models of pain: disease models and outcome measures. J Pain 14:1255-1269.

Gudin JA, Mogali S, Jones JD, Comer SD (2013) Risks, management, and monitoring of combination opioid, benzodiazepines, and/or alcohol use. Postgrad Med 125:115-130.

Hall W (2001) Reducing the harms caused by cannabis use: the policy debate in Australia. Drug Alcohol Depend 62:163-174.

Hallgren M, Vancampfort D, Giesen ES, Lundin A, Stubbs B (2017) Exercise as treatment for alcohol use disorders: systematic review and metaanalysis. Br J Sports Med 51:1058-1064.

Hargreaves K, Dubner R, Brown F, Flores C, Joris J (1988) A new and sensitive method for measuring thermal nociception in cutaneous hyperalgesia Pain 32:77-88.

Hartung DM, McCarty D, Fu R, Wiest K, Chalk M, Gastfriend DR (2014) Extended-release naltrexone for alcohol and opioid dependence: a metaanalysis of healthcare utilization studies. J Subst Abuse Treat 47:113-121.
Hill C, Wesolowicz D, Robinson M, Boissoneault J (2018) Sex differences in the acute analgesic effects of a subintoxicating dose of alcohol in healthy social drinkers. Alcohol Clin Exp Res 42:188A.

Hoffmann NG, Olofsson O, Salen B, Wickstrom L (1995) Prevalence of abuse and dependency in chronic pain patients. Int J Addict 30:919-927.

Holgate JY, Shariff M, Mu EW, Bartlett S (2017) A Rat drinking in the dark model for studying ethanol and sucrose consumption. Front Behav Neurosci 11:29.

Hu Y, Cui Z, Fan M, Pei Y, Wang Z (2018) Effects of acute alcohol intoxication on empathic neural responses for pain. Front Hum Neurosci 11:640

Imtiaz S, Loheswaran G, Le Foll B, Rehm J (2018) Longitudinal alcohol consumption patterns and health-related quality of life: results from the National Epidemiologic Survey on Alcohol and Related Conditions. Drug Alcohol Rev 37:48-55.

Itoga CA, Roltsch Hellard EA, Whitaker AM, Lu YL, Schreiber AL, Baynes BB, Baiamonte BA, Richardson HN, Gilpin NW (2016) Traumatic stress promotes hyperalgesia via corticotropin-releasing factor-1 receptor (CRFR1) signaling in central amygdala. Neuropsychopharmacology 41:2463-2472.

Jakubczyk A, Ilgen MA, Bohnert AS, Kopera M, Krasowska A, Klimkiewicz A, Blow FC, Brower KJ, Wojnar M (2015) Physical pain in alcoholdependent patients entering treatment in poland-prevalence and correlates. J Stud Alcohol Drugs 76:607-614.

Jakubczyk A, Ilgen MA, Kopera M, Krasowska A, Klimkiewicz A, Bohnert A, Blow FC, Brower KJ, Wojnar M (2016) Reductions in physical pain predict lower risk of relapse following alcohol treatment. Drug Alcohol Depend 158:167-171.

Ji D, Gilpin NW, Richardson HN, Rivier CL, Koob GF (2008) Effects of naltrexone, duloxetine, and a corticotropin-releasing factor type 1 receptor antagonist on binge-like alcohol drinking in rats. Behav Pharmacol 19:112.

Jones CM, Paulozzi LJ, Mack KA (2014) Alcohol involvement in opioid pain reliever and benzodiazepine drug abuse-related emergency department visits and drug-related deaths - United States, 2010. MMWR Morb Mortal Wkly Rep 63:881-885.

Kang S, Li J, Zuo W, Chen P, Gregor D, Fu R, Han X, Bekker A, Ye JH (2019) Downregulation of M-channels in lateral habenula mediates hyperalgesia during alcohol withdrawal in rats. Sci Rep 9:2714.

Katz PS, Sulzer JK, Impastato RA, Teng SX, Rogers EK, Molina PE (2015) Endocannabinoid degradation inhibition improves neurobehavioral function, blood-brain barrier integrity, and neuroinflammation following mild traumatic brain injury. J Neurotrauma 32:297-306.

Kelley ML, Bravo AJ, Votaw VR, Stein E, Redman JC, Witkiewitz K (2018) Opioid and sedative misuse among veterans wounded in combat. Addict Behav 92:168-172.

Khan S, Okuda M, Hasin DS, Secades-Villa R, Keyes K, Lin KH, Grant B, Blanco C (2013) Gender differences in lifetime alcohol dependence: results from the national epidemiologic survey on alcohol and related conditions. Alcohol Clin Exp Res 37:1696-1705.

Kononoff J, Kallupi M, Kimbrough A, Conlisk D, de Guglielmo G, George $\mathrm{O}$ (2018) Systemic and intra-habenular activation of the orphan $\mathrm{G}$ proteincoupled receptor GPR139 decreases compulsive-like alcohol drinking and hyperalgesia in alcohol-dependent rats. eNeuro 5:pii: ENEURO.015318.2018.

Korthuis PT, Lum PJ, Vergara-Rodriguez P, Ahamad K, Wood E, Kunkel LE, Oden NL, Lindblad R, Sorensen JL, Arenas V, Ha D, Mandler RN, McCarty D, CTN-0055 CHOICES Investigators (2017) Feasibility and safety of extended-release naltrexone treatment of opioid and alcohol use disorder in HIV clinics: a pilot/feasibility randomized trial. Addiction 112:1036-1044.

Kranzler HR, Soyka M (2018) Diagnosis and pharmacotherapy of alcohol use disorder: a review. JAMA 320:815-824.

Kranzler HR, Zhou H, Kember RL, Vickers Smith R, Justice AC, Damrauer S, Tsao PS, Klarin D, Baras A, Reid J, Overton J, Rader DJ, Cheng Z, Tate JP, Becker WC, Concato J, Xu K, Polimanti R, Zhao H, Gelernter J (2019) Genome-wide association study of alcohol consumption and use 
disorder in 274,424 individuals from multiple populations. Nat Commun 10:1499.

Landsman-Blumberg PB, Katz N, Gajria K, Coutinho AD, Yeung PP, White R (2017) Burden of alcohol abuse or dependence among long-term opioid users with chronic noncancer pain. J Manag Care Spec Pharm 23:718-724.

Larance B, Campbell G, Peacock A, Nielsen S, Bruno R, Hall W, Lintzeris N, Cohen M, Degenhardt L (2016) Pain, alcohol use disorders and risky patterns of drinking among people with chronic non-cancer pain receiving long-term opioid therapy. Drug Alcohol Depend 162:79-87.

Latif ZE, Solli KK, Opheim A, Kunoe N, Benth JS, Krajci P, Sharma-Haase K, Tanum L (2019) No increased pain among opioid-dependent individuals treated with extended-release naltrexone or buprenorphine-naloxone: a 3-month randomized study and 9-month open-treatment follow-up study. Am J Addict 28:77-85.

Le Bars D, Gozariu M, Cadden SW (2001) Animal models of nociception. Pharmacol Rev 53:597-652.

Lee J, Mukhopadhyay P, Matyas C, Trojnar E, Paloczi J, Yang YR, Blank BA, Vendruscolo JCM, Koob GF, Vendruscolo LF, Pacher P, Lohoff FW (in press) PCSK9 inhibition as novel therapeutic target for alcoholic liver disease. Sci Rep 9:17167.

Lee JS, Sorcher JL, Rosen AD, Damadzic R, Sun H, Schwandt M, Heilig M, Kelly J, Mauro KL, Luo A, Rosoff D, Muench C, Jung J, Kaminsky ZA, Lohoff FW (2018) Genetic association and expression analyses of the phosphatidylinositol-4-phosphate 5-kinase (PIP5K1C) gene in alcohol use disorder-relevance for pain signaling and alcohol use. Alcohol Clin Exp Res 42:1034-1043.

Lieber CS, DeCarli LM (1982) The feeding of alcohol in liquid diets: two decades of applications and 1982 update. Alcohol Clin Exp Res 6:523531 .

Linnstaedt SD, Walker MG, Parker JS, Yeh E, Sons RL, Zimny E, Lewandowski C, Hendry PL, Damiron K, Pearson C, Velilla MA, O’Neil BJ, Jones J, Swor R, Domeier R, Hammond S, McLean SA (2015) MicroRNA circulating in the early aftermath of motor vehicle collision predict persistent pain development and suggest a role for microRNA in sex-specific pain differences. Mol Pain 11:66.

Litten RZ, Egli M, Heilig M, Cui C, Fertig JB, Ryan ML, Falk DE, Moss H, Huebner R, Noronha A (2012) Medications development to treat alcohol dependence: a vision for the next decade. Addict Biol 17:513-527.

Liu C, Bonaventure P, Lee G, Nepomuceno D, Kuei C, Wu J, Li Q, Joseph V, Sutton SW, Eckert W, Yao X, Yieh L, Dvorak C, Carruthers N, Coate H, Yun S, Dugovic C, Harrington A, Lovenberg TW (2015) GPR139, an orphan receptor highly enriched in the habenula and septum, is activated by the essential amino acids L-tryptophan and L-phenylalanine. Mol Pharmacol 88:911-925.

Macfarlane GJ, Beasley M (2015) Alcohol consumption in relation to risk and severity of chronic widespread pain: results from a UK populationbased study. Arthritis Care Res 67:1297-1303.

Magill M, Ray LA (2009) Cognitive-behavioral treatment with adult alcohol and illicit drug users: a meta-analysis of randomized controlled trials. J Stud Alcohol Drugs 70:516-527.

Manubay J, Davidson J, Vosburg S, Jones J, Comer S, Sullivan M (2015) Sex differences among opioid-abusing patients with chronic pain in a clinical trial. J Addict Med 9:46-52.

McCabe SE, Cranford JA, Morales M, Young A (2006) Simultaneous and concurrent polydrug use of alcohol and prescription drugs: prevalence, correlates, and consequences. J Stud Alcohol 67:529-537.

McCracken LML, Vowles KE (2014) Acceptance and commitment therapy and mindfulness for chronic pain: model, process, and progress. Am Psychol 69:178-187.

McDermott KA, Joyner KJ, Hakes JK, Okey SA, Cougle JR (2018) Pain interference and alcohol, nicotine, and cannabis use disorder in a national sample of substance users. Drug Alcohol Depend 186:53-59.

Meints SM, Wang V, Edwards RR (2018) Sex and race differences in pain sensitization among patients with chronic low back pain. J Pain 19:14611470.
Meng W, Adams MJ, Hebert HL, Deary IJ, McIntosh AM, Smith BH (2018) A genome-wide association study finds genetic associations with broadly-defined headache in UK biobank $(\mathrm{N}=223,773)$. EBioMedicine 28:180-186.

Mogil JS (2012) Sex differences in pain and pain inhibition: multiple explanations of a controversial phenomenon. Nat Rev Neurosci 13:859-66.

Mogil JS, Davis KD, Derbyshire SW (2010) The necessity of animal models in pain research. Pain 151:12-17.

Morasco BJ, Greaves DW, Lovejoy TI, Turk DC, Dobscha SK, Hauser P (2016) Development and preliminary evaluation of an integrated cognitive-behavior treatment for chronic pain and substance use disorder in patients with the hepatitis C virus. Pain Med 17:2280-2290.

Morena M, Patel S, Bains JS, Hill MN (2016) Neurobiological interactions between stress and the endocannabinoid system. Neuropsychopharmacology 41:80-102.

Moskal D, Maisto SA, De Vita M, Ditre JW (2018) Effects of experimental pain induction on alcohol urge, intention to consume alcohol, and alcohol demand. Exp Clin Psychopharmacol 26:65-76.

Mücke M, Phillips T, Radbruch L, Petzke F, Häuser W (2018) Cannabisbased medicines for chronic neuropathic pain in adults. Cochrane Database Syst Rev 3:Cd012182.

Nohr AC, Shehata MA, Hauser AS, Isberg V, Mokrosinski J, Andersen KB, Farooqi IS, Pedersen DS, Gloriam DE, Brauner-Osborne H (2017) The orphan G protein-coupled receptor GPR139 is activated by the peptides: adrenocorticotropic hormone (ACTH), alpha-, and beta-melanocyte stimulating hormone (alpha-MSH, and beta-MSH), and the conserved core motif HFRW. Neurochem Int 102:105-113.

Novak SP, Peiper NC, Zarkin GA (2016) Nonmedical prescription pain reliever and alcohol consumption among cannabis users. Drug Alcohol Depend 159:101-108.

Nugraha B, Gutenbrunner C, Barke A, Karst M, Schiller J, Schäfer P, Falter S, Korwisi B, Rief W, Treede R-D, Pain ITftCoC, (2019) The IASP classification of chronic pain for ICD-11. Pain 160:88-94.

Oliveros A, Choi DS (2017) Repurposing tigecycline for the treatment of alcohol use disorder. Alcohol Clin Exp Res 41:497-500.

Ong WY, Stohler CS, Herr DR (2019) Role of the prefrontal cortex in pain processing. Mol Neurobiol 56:1137-1166.

Pahng AR, Edwards S (2018) Measuring pain avoidance-like behavior in drug-dependent rats. Curr Protoc Neurosci 85:e53.

Pahng AR, Paulsen RI, McGinn MA, Edwards KN, Edwards S (2017) Neurobiological correlates of pain avoidance-like behavior in morphine-dependent and non-dependent rats. Neuroscience 366:1-14.

Patberg WR, Rasker JJ, van de Wiel A (1999) Dual effect of alcohol on pain in rheumatoid arthritis. J Rheumatol 26:1215.

Patten DK, Schultz BG, Berlau DJ (2018) The safety and efficacy of lowdose naltrexone in the management of chronic pain and inflammation in multiple sclerosis, fibromyalgia, crohn's disease, and other chronic pain disorders. Pharmacotherapy 38:382-389.

Petre B, Torbey S, Griffith JW, De Oliveira G, Herrmann K, Mansour A, Baria AT, Baliki MN, Schnitzer TJ, Apkarian AV (2015) Smoking increases risk of pain chronification through shared corticostriatal circuitry. Hum Brain Mapp 36:683-694.

Ralevski E, Perrino A, Acampora G, Koretski J, Limoncelli D, Petrakis I (2010) Analgesic effects of ethanol are influenced by family history of alcoholism and neuroticism. Alcohol Clin Exp Res 34:1433-1441.

Randall LO, Selitto JJ (1957) A method for measurement of analgesic activity on inflamed tissue. Arch Int Pharmacodyn Ther 111:409-419.

Ray LA, Bujarski S, Roche DJO, Magill M (2018) Overcoming the "Valley of Death" in medications development for alcohol use disorder. Alcohol Clin Exp Res 42:1612-1622.

Reddy KS, Naidu MU, Rani PU, Rao TR (2012) Human experimental pain models: a review of standardized methods in drug development. J Res Med Sci 17:587-595.

Richards CJ, Graf KW Jr, Mashru RP (2017) The Effect of opioids, alcohol, and nonsteroidal anti-inflammatory drugs on fracture union. Orthop Clin North Am 48:433-443. 
Richter CP, Campbell KH (1940) Alcohol taste thresholds and concentrations of solution preferred by rats. Science 91:507-508.

Riley JL, King C (2009) Self-report of alcohol use for pain in a multi-ethnic community sample. J Pain 10:944-952.

Roberto M, Cruz MT, Gilpin NW, Sabino V, Schweitzer P, Bajo M, Cottone P, Madamba SG, Stouffer DG, Zorrilla EP, Koob GF, Siggins GR, Parsons LH (2010) Corticotropin releasing factor-induced amygdala gammaaminobutyric acid release plays a key role in alcohol dependence. Biol Psychiatry 67:831-839.

Robins MT, Heinricher MM, Ryabinin AE (2019) From pleasure to pain, and back again: the intricate relationship between alcohol and nociception. Alcohol Alcohol 54:625-638.

Roltsch Hellard EA, Impastato RA, Gilpin NW (2017) Intra-cerebral and intra-nasal melanocortin-4 receptor antagonist blocks withdrawal hyperalgesia in alcohol-dependent rats. Addict Biol 22:692-701.

Roos CR, Mann K, Witkiewitz K (2017) Reward and relief dimensions of temptation to drink: construct validity and role in predicting differential benefit from acamprosate and naltrexone. Addict Biol 22:1528-1539.

Rosen S, Ham B, Mogil JS (2017) Sex differences in neuroimmunity and pain. J Neurosci Res 95:500-508.

Sacks JJ, Gonzales KR, Bouchery EE, Tomedi LE, Brewer RD (2015) 2010 National and state costs of excessive alcohol consumption. Am J Prev Med 49:e73-e79.

Sakaguchi T, Iwasaki S, Okada M, Okamoto K, Ikegaya Y (2018) Ethanol facilitates socially evoked memory recall in mice by recruiting pain-sensitive anterior cingulate cortical neurons. Nat Commun 9:3526.

Schepis TS, Teter CJ, Simoni-Wastila L, McCabe SE (2018) Prescription tranquilizer/sedative misuse prevalence and correlates across age cohorts in the US. Addict Behav 87:24-32.

Silberstein SD (2017) Topiramate in migraine prevention: a 2016 perspective. Headache 57:165-178.

Simms JA, Steensland P, Medina B, Abernathy KE, Chandler LJ, Wise R, Bartlett SE (2008) Intermittent access to $20 \%$ ethanol induces high ethanol consumption in Long-Evans and Wistar rats. Alcohol Clin Exp Res 32:1816-1823.

Smith ML, Hostetler CM, Heinricher MM, Ryabinin AE (2016) Social transfer of pain in mice. Sci Adv 2:e1600855.

Smith ML, Walcott AT, Heinricher MM, Ryabinin AE (2017) Anterior cingulate cortex contributes to alcohol withdrawal-induced and socially transferred hyperalgesia. eNeuro 4:pii: ENEURO.0087-17.2017.

Sorge RE, Totsch SK (2017) Sex differences in pain. J Neurosci Res 95:12711281.

Stacy AW, Widaman KF, Marlatt GA (1990) Expectancy models of alcohol use. J Pers Soc Psychol 58:918-928.

Stahre M, Roeber J, Kanny D, Brewer RD, Zhang X (2014) Contribution of excessive alcohol consumption to deaths and years of potential life lost in the United States. Prev Chronic Dis 11:130293.

Stein ER, Gibson BC, Votaw VR, Wilson AD, Clark VP, Witkiewitz K (2018) Non-invasive brain stimulation in substance use disorders: implications for dissemination to clinical settings. Curr Opin Psychol 30:6-10.

Stewart SH, Finn PR, Pihl RO (1995) A dose-response study of the effects of alcohol on the perceptions of pain and discomfort due to electric shock in men at high familial-genetic risk for alcoholism. Psychopharmacology 119:261-267.

Subbaraman MS, Kerr WC (2019) Subgroup trends in alcohol and cannabis co-use and related harms during the rollout of recreational cannabis legalization in Washington state. Int J Drug Policy pii: S0955-3959(19)30181-1. https://doi.org/10.1016/j.drugpo.2019.07.003

Substance Abuse and Mental Health Services Administration (2018) Key substance use and mental health indicators in the United States: Results from the 2017 National Survey on Drug Use and Health (HHS Publication No. SMA 18-5068, NSDUH Series H-53)., in Series Key substance use and mental health indicators in the United States: Results from the 2017 National Survey on Drug Use and Health (HHS Publication No. SMA 18-5068, NSDUH Series H-53). Center for Behavioral Health
Statistics and Quality, Substance Abuse and Mental Health Services Administration, Rockville, MD.

Suri P, Palmer MR, Tsepilov YA, Freidin MB, Boer CG, Yau MS, Evans DS, Gelemanovic A, Bartz TM, Nethander M, Arbeeva L, Karssen L, Neogi T, Campbell A, Mellstrom D, Ohlsson C, Marshall LM, Orwoll E, Uitterlinden A, Rotter JI, Lauc G, Psaty BM, Karlsson MK, Lane NE, Jarvik GP, Polasek O, Hochberg M, Jordan JM, Van Meurs JBJ, Jackson R, Nielson CM, Mitchell BD, Smith BH, Hayward C, Smith NL, Aulchenko YS, Williams FMK (2018) Genome-wide meta-analysis of 158,000 individuals of European ancestry identifies three loci associated with chronic back pain. PLoS Genet 14:e1007601.

Tappe-Theodor A, King T, Morgan MM (2019) Pros and cons of clinically relevant methods to assess pain in rodents. Neurosci Biobehav Rev 100:335-343.

Thiele TE, Navarro M (2014) "Drinking in the dark" (DID) procedures: a model of binge-like ethanol drinking in non-dependent mice. Alcohol 48:235-241.

Thompson T, Oram C, Correll CU, Tsermentseli S, Stubbs B (2017) Analgesic effects of alcohol: a systematic review and meta-analysis of controlled experimental studies in healthy participants. J Pain 18:499-510.

Tunstall BJ, Vendruscolo LF, Allen-Worthington K (2019) Alcohol use disorder research, in The Laboratory Rat (Suckow M, Wilson R, Foley P, Hankenson FC, eds), pp. 967-986. Elsevier, New York, NY.

Turna J, Syan SK, Frey BN, Rush B, Costello MJ, Weiss M, MacKillop J (2019) Cannabidiol as a novel candidate alcohol use disorder pharmacotherapy: a systematic review. Alcohol Clin Exp Res 43:550-563.

Vaeth PA, Wang-Schweig M, Caetano R (2017) Drinking, alcohol use disorder, and treatment access and utilization among U.S. racial/ethnic groups. Alcohol Clin Exp Res 41:6-19.

Vendruscolo LF, Barbier E, Schlosburg JE, Misra KK, Whitfield TW, Logrip Ml, Rivier C, Repunte-Canonigo V, Zorrilla EP, Sanna PP, Heilig M, Koob GF (2012) Corticosteroid-dependent plasticity mediates compulsive alcohol drinking in rats. J Neurosci 32:7563-7571.

Vendruscolo LF, Estey D, Goodell V, Macshane LG, Logrip ML, Schlosburg JE, McGinn MA, Zamora-Martinez ER, Belanoff JK, Hunt HJ, Sanna PP, George O, Koob GF, Edwards S, Mason BJ (2015) Glucocorticoid receptor antagonism decreases alcohol seeking in alcohol-dependent individuals. J Clin Invest 125:3193-3197.

Vendruscolo LF, Pamplona FA, Takahashi RN (2004) Strain and sex differences in the expression of nociceptive behavior and stress-induced analgesia in rats. Brain Res 1030:277-283.

Vendruscolo LF, Roberts AJ (2014) Operant alcohol self-administration in dependent rats: focus on the vapor model. Alcohol 48:277-286.

Votaw VR, Witkiewitz K, Valeri L, Bogunovic O, McHugh RK (2019) Nonmedical prescription sedative/tranquilizer use in alcohol and opioid use disorders. Addict Behav 88:48-55.

Vowles KE, Witkiewitz K, Pielech M, Edwards KA, McEntee ML, Bailey RW, Bolling L, Sullivan MD (2018) Alcohol and opioid use in chronic pain: a cross-sectional examination of differences in functioning based on misuse status. J Pain 19:1181-1188.

Walcott AT, Smith ML, Loftis JM, Ryabinin AE (2018) Social transfer of alcohol withdrawal-induced hyperalgesia in female prairie voles. Soc Neurosci 13:710-717.

Weinberger AH, Platt J, Goodwin RD (2016) Is cannabis use associated with an increased risk of onset and persistence of alcohol use disorders? A three-year prospective study among adults in the United States. Drug Alcohol Depend 161:363-367.

Williams EC, Gupta S, Rubinsky AD, Jones-Webb R, Bensley KM, Young JP, Hagedorn H, Gifford E, Harris AH (2016) Racial/ethnic differences in the prevalence of clinically recognized alcohol use disorders among patients from the U.S. Veterans Health Administration. Alcohol Clin Exp Res 40:359-366.

Wilson S, Bair JL, Thomas KM, Iacono WG (2017) Problematic alcohol use and reduced hippocampal volume: a meta-analytic review. Psychol Med 47:2288-2301. 
Wise RA (1973) Voluntary ethanol intake in rats following exposure to ethanol on various schedules. Psychopharmacologia 29:203-210.

Witbrodt J, Mulia N, Zemore SE, Kerr WC (2014) Racial/ethnic disparities in alcohol-related problems: differences by gender and level of heavy drinking. Alcohol Clin Exp Res 38:1662-1670.

Witkiewitz K, Vowles KE (2018) Alcohol and opioid use, co-use, and chronic pain in the context of the opioid epidemic: a critical review. Alcohol Clin Exp Res 42:478-488.

Witkiewitz K, Vowles KE, McCallion E, Frohe T, Kirouac M, Maisto SA (2015) Pain as a predictor of heavy drinking and any drinking lapses in the COMBINE study and the UK Alcohol Treatment Trial. Addiction 110:1262-1271.

Woodrow KM, Eltherington LG (1988) Feeling no pain: alcohol as an analgesic. Pain 32:159-163.

Woolfe G, Macdonald AD (1944) The evaluation of the analgesic action of pethidine hydrochloride (Demerol). J Pharmacol Exp Ther 80:300307.

World Health Organization (2018) Global Status Report on Alcohol and Health 2018, in Series Global status report on alcohol and health 2018. World Health Organization, Geneva Switzerland.
Wright BD, Loo L, Street SE, Ma A, Taylor-Blake B, Stashko MA, Jin J, Janzen WP, Frye SV, Zylka MJ (2014) The lipid kinase PIP5K1C regulates pain signaling and sensitization. Neuron 82:836-847.

Yardley MM, Ray LA (2017) Medications development for the treatment of alcohol use disorder: insights into the predictive value of animal and human laboratory models. Addict Biol 22:581-615.

Yeung EW, Craggs JG, Gizer IR (2017) Comorbidity of alcohol use disorder and chronic pain: genetic influences on brain reward and stress systems. Alcohol Clin Exp Res 41:1831-1848.

Yu W, Hwa LS, Makhijani VH, Besheer J, Kash TL (2019) Chronic inflammatory pain drives alcohol drinking in a sex-dependent manner for C57BL/6J mice. Alcohol 77:135-145.

Zale EL, LaRowe LR, Boissoneault J, Maisto SA, Ditre JW (2019) Gender differences in associations between pain-related anxiety and alcohol use among adults with chronic pain. Am J Drug Alcohol Abuse 45:479-487.

Zale EL, Maisto SA, Ditre JW (2015) Interrelations between pain and alcohol: an integrative review. Clin Psychol Rev 37:57-71.

Zhang L, Kline RH, McNearney TA, Johnson MP, Westlund KN (2014) Cannabinoid receptor 2 agonist attenuates pain related behavior in rats with chronic alcohol/high fat diet induced pancreatitis. Mol Pain 10:66. 